\title{
Article
}

\section{Interpreting physical performance in professional soccer match-play: Should we be more pragmatic in our approach?}

\author{
Carling, C.
}

Available at https://clok.uclan.ac.uk/12262/

Carling, C. orcid iconORCID: 0000-0002-7456-3493 (2013) Interpreting physical performance in professional soccer match-play: Should we be more pragmatic in our approach? Sports Medicine, 43 (8). pp. 655-663. ISSN 01121642

It is advisable to refer to the publisher's version if you intend to cite from the work. http://dx.doi.org/10.1007/s40279-013-0055-8

For more information about UCLan's research in this area go to http://www.uclan.ac.uk/researchgroups/ and search for <name of research Group>.

For information about Research generally at UCLan please go to http://www.uclan.ac.uk/research/

All outputs in CLoK are protected by Intellectual Property Rights law, including Copyright law. Copyright, IPR and Moral Rights for the works on this site are retained by the individual authors and/or other copyright owners. Terms and conditions for use of this material are defined in the policies page. 
This is a pre-proof corrected manuscript, as accepted for publication, of an article published by Springer International Publishing in Sports Medicine in August 2013. The final publication is available at link.springer.com: http://link.springer.com/article/10.1007/s40279-013-0055-8

\section{PLEASE REFER TO THE PUBLISHED VERSION FOR CITING PURPOSES}

Interpreting physical performance in professional soccer match-play: should we be more pragmatic in our approach?

Running head: Physical performance in professional soccer match-play

Acknowledgement: The author has no potential conflict of interest and no funding was obtained for the preparation of this article.

Word count: 4934 
Interpreting physical performance in professional soccer match-play: should we be more pragmatic in our approach?

Author: Christopher Carling ${ }^{1,2}$

Institutions:

${ }^{1}$ Institute of Coaching and Performance, University of Central Lancashire, Preston, United Kingdom,

${ }^{2}$ LOSC Lille Metropole Football Club, Domain de Luchin, Camphin-en-Pévèle, 59780, France,

Correspondance: LOSC Lille Metropole Football Club, Domain de Luchin, Camphin-en-Pévèle, 59780, France.

Phone: 00.33.6.0392 1863

Fax: 00.33.1.48910793

Email: chris.carling@free.fr 


\begin{abstract}
Academic and practitioner interest in the physical performance of male professional soccer players in the competition setting determined via time-motion analyses has grown substantially over the last four decades leading to a substantial body of published research and aiding development of a more systematic evidence-based framework for physical conditioning. Findings have forcibly shaped contemporary opinions in the sport with researchers and practitioners frequently emphasising the important role that physical performance plays in match outcomes. Time-motion analyses have also influenced practice as player conditioning programmes can be tailored according to the different physical demands identified across individual playing positions. Yet despite a more systematic approach to physical conditioning, data indicate that even at the very highest standards of competition, the contemporary player is still susceptible to transient and end-game fatigue. Over the course of this article, the author suggests that a more pragmatic approach to interpreting the current body of timemotion analysis data and its application in the practical setting is nevertheless required. Examples of this are addressed using findings in the literature to examine: a) the association between competitive physical performance and 'success' in professional soccer, b) current approaches to interpreting differences in time-motion analysis data across playing positions and, c) whether data can realistically be used to demonstrate the occurrence of fatigue in match-play. Gaps in the current literature and directions for future research are also identified.
\end{abstract}




\section{Interpreting physical performance in professional soccer match-play: should we be more pragmatic in our approach?}

\section{Introduction}

Academic and practitioner interest in the physical performance of male professional soccer players in the competition setting determined using time-motion analysis has grown substantially over the last four decades leading to a large body of published research and a more systematic evidencebased approach to physical conditioning. ${ }^{[1]}$ This work has enabled identification of a substantial increase in the physical demands observed in competition notably for the total distance covered ${ }^{[2]}$ and that run in high-speed running activity ${ }^{1}{ }^{[3]}$ This increase in competitive demands has forcibly shaped contemporary opinions with researchers and practitioners frequently emphasising the importance of physical performance and its link to match outcomes at the highest levels of play. ${ }^{[4-8]}$ The present train of thought also stems from earlier studies reporting that player fitness levels and competitive physical performance at professional standards were superior to those observed in peers at lower standards of play ${ }^{[9-11]}$ suggesting that the athletic component of the game separates the best teams and players from the rest.

Time motion analysis research has also influenced training practice as physical conditioning programmes can be tailored according to the differences in athletic demands commonly observed across individual playing positions to suit the specific needs of each role and the game situations commonly experienced. ${ }^{[11-19]}$ Despite a more systematic approach to physical conditioning, statistically significant declines in running activities are apparent indicating a susceptibility to fatigue and an inability to consistently perform at the same level over the course of play even at the highest standards of contemporary competition. ${ }^{[5,6,11,12,14 ; 16 ; 17 ; 19-23]}$ In this article, the author nevertheless suggests that there is a need for a more pragmatic approach to interpreting the current body of time-motion analysis data and its subsequent application in the training setting. Examples of this are addressed using findings in the literature to examine: a) the association between competitive physical performance and 'success' in professional soccer, b) current approaches to interpreting differences in time-motion analysis data across playing positions and, c) whether data can realistically be used to demonstrate the occurrence of fatigue in match-play. Gaps in the current literature and directions for future research are also identified.

\footnotetext{
${ }^{1}$ Due to inconsistencies in terminology and definitions of high-intensity type running activity in the studies cited throughout this article, the term "high-speed" activity was preferred here. Unless stated, discrete 'high-intensity' and 'sprinting' activities are encompassed under the "high-speed" activity definition. The speed threshold in $\mathrm{km} / \mathrm{h}$ used for discrete high-speed activities in each study is provided where possible.
} 


\section{The association between competitive physical performance and 'success' in professional soccer}

Time motion analyses of match activity and particularly high-speed running in relation to league position at the end of the playing season has been used to provide an indication of the extent to which physical performance can influence the 'success' of teams. Two studies conducted in the top professional Leagues in England ${ }^{[5]}$ and Italy ${ }^{[22]}$ respectively have reported an association between physical output and final League ranking. Perhaps surprisingly, considering the current train of thought, lower-ranked teams in both Leagues covered significantly greater distances in high-speed movement activity. In English Premier League players the distances covered at speeds $>19.8 \mathrm{~km} / \mathrm{h}$ and $>25.2 \mathrm{~km} / \mathrm{h}$ respectively were greater in both middle- and bottom-ranked teams compared with Top5ranked peers (both $\mathrm{p}<0.05$ ) with substantial differences also observed across certain playing positions. In the Italian Serie A League, similar findings were reported in players belonging to the five highestranked teams compared to peers in the five lowest-ranked teams. The distances covered in high-speed $(>14.0 \mathrm{~km} / \mathrm{h})$ and very high-speed running $(>19.0 \mathrm{~km} / \mathrm{h})$ were substantially higher in the latter $( \pm 11 \%$ and $\pm 9 \%$ respectively, both $\mathrm{p}<0.01$ ). Research conducted in the same League has also reported a greater total distance covered and that run in high-speed activity $(>14.4 \mathrm{~km} / \mathrm{h})$ in players in a reference Serie A team competing against 'better' opponents (teams participating in the Champions League and those finishing in the top eight places in its National League) in comparison to that in games against lower-ranked teams in the League $(\mathrm{p}<0.05) \cdot{ }^{[21]}$ Related work has compared activity profiles captured from players in the highest and second highest standards of English football (Premier League versus Championship). ${ }^{[24]}$ Greater physical demands (total distance run and that covered in high-speed running and sprinting, $\mathrm{p}<0.05$ to $\mathrm{p}<0.001$ ) were observed in Championship players compared to Premier League peers although the small effect sizes reported for the statistical differences suggest these were negligible in practical terms. Unfortunately, the data did not account for potential differences in the physical capacities of players across standards.

On the whole, these observations suggest that factors other than physical performance represented by high-speed activity per se are more important in achieving success. Overall technical and tactical effectiveness probably have a greater impact on results and teams' final League ranking. Unpublished data from the French top-flight (Ligue 1) show that during the 2010/2011 season, the Championship winning team was ranked in the top three clubs for goals scored, ball possession, completed passes and crosses, shots and shots on target. In contrast, the same team was placed $9^{\text {th }}$ out of 20 clubs for total distance run and $8^{\text {th }}$ for high-speed activity $(>21 \mathrm{~km} / \mathrm{h})$ respectively although time motion data were unavailable for every match played (Carling, unpublished data). Information from the two aforementioned studies on English Premier League ${ }^{[5]}$ and Italian Serie $\mathrm{A}^{[22]}$ soccer partly support this theory as comparison of differences in the distance covered at high-speeds between 'successful' and 'less successful' teams identified large discrepancies in efforts in relation to time spent in and out of ball possession. The frequency of ball possessions, short and long passes, 
completed short and long passes, shots and shots on target was also higher in the more successful Italian teams. The greater high-speed activity observed in lower-ranked teams would seem to be a direct consequence of their attempts to regain and perhaps inability to maintain ball possession. ${ }^{[5]}$ Similar work across multiple National Championships internationally is necessary to ensure a more valid representation of contemporary soccer play.

Despite the relatively low number of published studies presented here, three questions can be formulated regarding the impact of current information derived from time-motion analyses:

1) Is it really worthwhile comparing the physical performance and particularly high-speed activity in one's team with that observed in direct opponents and/or with averages across Leagues if these are not discriminating components in achieving success at the very highest levels of play? Furthermore, all high speed type efforts in competition are subject to large 'natural' variation (coefficients of variation $[\% \mathrm{CV}]$ ranging from $16-30 \%{ }^{[25]}$ ) between successive matches and/or across the competitive season. ${ }^{[5]}$ The variability in physical performance is mediated through the inherent demands of the game that are influenced by a myriad of factors such as own and opponent playing style, team formation and tactics, and individual fitness characteristics thereby affecting players' ability to regulate personal activity. ${ }^{[1]}$ In some individuals, the tactical elements of play and contextual factors such as score line will drive physical efforts hence some players' physical capacity might or might not be fully tested. Analysis of $\% \mathrm{CV}$ in physical outputs according to team ranking to determine whether performance is more 'consistent' in top ranked teams is warranted. However, time motion data are often unavailable for every single game played across the season and injury and non selection of players and international call ups can impact on player fitness and 'freshness' and eventually competitive physical performance. Combined, these points lead to major difficulties in interpreting the real world utility and eventual applicability of data.

2) Should coaching and fitness personnel simply disregard attempts to relate physical performance to success and aim towards achieving what could be deemed an 'adequate' level of player fitness (e.g., determined by scores in an intermittent field test) in order to attain League averages for team and position specific physical performance? For example, a total distance run ranging from $10-12 \mathrm{~km}$ of which $6-10 \%$ is covered in high-speed activity ${ }^{[1]}$. Of interest, recent research in 124 elite Under-13 to Under-18 players has shown that individual fitness did not directly limit highspeed running activity and enhancements in players' physical condition did not always lead to a concomitant improvement in match running performance. ${ }^{[26]}$ While similar large-scale research is warranted in players at professional standards, should greater emphasis be placed on enhancing tactical and technical performance and developing game intelligence, decision making and anticipation skills especially at youth levels? A recent investigation reported that out of a sample of 360 goals scored during the 2007/08 German Bundesliga League season, the majority (83\%) was preceded by a 'sprinting' action (although movement speeds were evaluated subjectively) performed by the player who either scored the goal or provided the goal assist. ${ }^{[8]}$ Should researchers and practitioners attempt 
therefore to 'qualitatively' evaluate the tactical 'utility' of high-speed actions both in attacking and defending play rather than distance covered in high-speed running per se? Research is necessary to investigate the interaction between the athletic, behavioural, tactical and technical components of performance rather than studying these in isolation. Information from interviews conducted with practitioners and players from teams across different playing standards and rankings regarding their perceptions of athletic performance especially in relation to these other game components would also be pertinent. Do coaching practitioners in lower-ranked teams for example consider that player 'work rate' plays a more important role in their teams' approach to matches compared to peers in top5 ranked teams?

3) On the basis of the above discussion, one can ask whether it is compulsory to invest the large amounts of time and finances currently necessary for collecting, analysing and interpreting physical performance data from competition settings ${ }^{[27]}$ especially if this component is not a discriminator of team success or perhaps even the ability to perform at the highest level. Similarly, while time motion analysis data can be used to complement information collected from monitoring player efforts in the training setting thereby aiding practitioners to quantify and manipulate weekly work load especially during periods of fixture congestion, ${ }^{[1]}$ do the numerous difficulties that are inherent to their interpretation (especially high-speed activity) identified earlier simply render their place in the performance analysis and physical conditioning process redundant?

\section{Current approaches to interpreting differences in time-motion analysis data across playing positions}

It is widely accepted since the earliest time motion analyses studies ${ }^{[28,29]}$ that significant differences exist in the general fitness components and competitive physical activity profiles across playing positions with these linked to the tactical demands specific to each role. A glut of more recent studies have reported statistically significant differences in the total distance covered and that run at a range of speeds according to playing position..$^{[2,4-7,11-19,23,24]}$ Recently, position-dependent demands have also been observed in the frequency of sprint actions $(>25.2 \mathrm{~km} / \mathrm{h})$ characterized by a fast (explosive) or gradual (leading) acceleration ${ }^{[4,5]}$ and the number of repeated high-speed bouts ${ }^{[13]}$ performed in competition. As such, researchers and practitioners systematically adopt a positionspecific approach to analysing and interpreting time motion analysis data. More importantly, this information enables the latter to design and prescribe tailored physical conditioning programmes. Concerns can be raised however in relation to the extent of these differences observed across playing positions and their subsequent application in training. In Table 1, examples of time-motion analysis data reported in three studies on professional soccer competition ${ }^{[4,13,16]}$ are used to highlight these concerns. 
3.1 Absolute versus relative interpretations of data: In the majority of time-motion analysis studies, physical activity data are frequently expressed as absolute values for distances covered at a range of speed thresholds. In study $\mathrm{I}^{[16]}$ analysis of the total distances travelled in high-speed running $(>19.8 \mathrm{~km} / \mathrm{h}$ ) shows that wide-midfielders ran a significantly greater distance compared to the other playing positions (all $\mathrm{p}<0.05$ ). Wide-midfielders also covered the largest distance overall suggesting they were subjected to substantially higher physical demands. Similarly, in Study II, ${ }^{[4]}$ the positional analysis of sprinting actions $(>25.2 \mathrm{~km} / \mathrm{h}$ ) categorised according to acceleration characteristics shows that in absolute terms, full-backs, wide-midfielders and attackers performed significantly more explosive type sprints than central-defenders and central-midfielders respectively (all $\mathrm{p}<0.01$ ). Accordingly, authors in these and other related studies have suggested the need for prescription of additional and/or position-specific high-intensity type training to respond to the 'greater' physical demands required in certain playing positions especially fullbacks and wide-midfielders.

Yet when the distances travelled at high-speeds in study I are expressed in relative terms or as a percentage of the total distance covered, the following results are obtained: fullbacks $=9.2 \%$, centraldefenders $=6.1 \%$, central-midfielders $=8.1 \%$, wide-midfielders $=10.5 \%$ and attackers $=9.3 \%$. Subsequently, the difference between mean percentages for players belonging to the midfield unit; wide-midfielders and central-midfielders for example, is equal to $+2.4 \%$. In study II, the frequency of explosive and leading sprints expressed as a percentage of the total number of sprint actions performed shows that results were similar across all positions: fullbacks $=23 \%$, central-defenders $=24 \%$, centralmidfielders $=24 \%$, wide-midfielders $=22 \%$ and attackers $=22 \%$.

Accordingly, a pragmatic question would be to ask whether a $2.4 \%$ difference in high-speed distance covered over 90-minutes play is meaningful enough to warrant prescription of additional training of this fitness component in wide- and not central-midfield players for example. In addition, the absolute data suggest that high-speed game demands in fullbacks are higher those in attackers (albeit non-significantly) whereas the same data expressed in relative terms indicate that a higher percentage of the total distance covered $(+0.1 \%)$ is actually covered by the latter. Thus in relation to the overall game demands, high-speed activity could be considered equally as, if not more important in attackers compared to fullbacks. The subsequent question which arises is to what extent positional differences in performance data have implications for training prescription and whether expressing information as a ' $\%$ ' figure alters a practitioner's interpretation or not. Ultimately practitioners might consider that the ability to perform a certain absolute amount of high speed running is still important irrespective of the $\%$ of the total distance run this accounts for as the large differences between positions will undoubtedly have important implications for conditioning. In the same context however, if an attacking player covers a high amount of high-speed running relative to their total distance then this probably remains an important component (despite the lower absolute value) and should not be ignored during fitness training prescription. Indeed, the similarities reported in study II in acceleration characteristics expressed relative to overall demands might imply that players across all positions 
follow similarly structured conditioning programmes to develop both explosive and leading sprint ability despite large differences in the absolute number of these actions.

A proposed solution to the absolute versus relative approach highlighted above has been to employ an individualised approach to analysing time motion data as a function of the pre-determined physiological capacity of each player in the team squad. ${ }^{[30]}$ The use of mean values for running distances averaged across several players in the same positional role does not take into account any differences in physiological capacity between individuals. For example, in 5 central midfield players belonging to the same professional soccer team, aerobic fitness determined via a continuous progressive incremental running test reported $\mathrm{VO}_{2 \max }$ data ranging from 60.2 to $64.8 \mathrm{~mL} / \mathrm{kg} / \mathrm{min}$ and blood lactate concentrations sampled at a running speed of $14 \mathrm{~km} / \mathrm{h}$ ranged from 3.0 to $5.8 \mathrm{mmol} / \mathrm{L}$ (Carling, personal data). Comparison of mean data and respective confidence intervals for time motion metrics expressed in relation to individualised physiological thresholds averaged for individuals in each playing position could help identify which if any particular role is more often required to work near and/or above their physiological capacity. This could have benefits for fitness training prescription for both team units as a whole and the individuals within each unit. However, consensus is still needed to determine on the most valid test to determine physiological thresholds that are representative of the intermittent and stochastic nature of soccer match-play. ${ }^{[30]}$

3.2 Physiological interpretations of positional differences: In study $\mathrm{I}^{[16]}$, the comparison of mean recovery times interspersing high-speed efforts shows that central- and wide-midfield players had significantly less time to recover following these actions compared to the other playing positions. However, it is worth interpreting these differences from a 'physiological' point of view. For example, the lowest recovery times observed in the wide-midfield players $(51 \pm 16 \mathrm{~s})$ could be deemed close enough to the 60s interval necessary to allow near complete physiological recovery during repeated high-speed type activity. ${ }^{[31]}$ Furthermore, the ability to recover fully following high-speed activity is aided by the relatively short length of intense bouts $(<20 \mathrm{~m})$ generally observed across all playing positions in professional soccer. ${ }^{[1]}$ Therefore, the pertinence of individualised conditioning programmes prescribed in an attempt to increase wide-midfield players' physiological capacity to resist fatigue, recover quickly and subsequently reproduce intense efforts over brief match periods might be questionable.

3.3 Relevance of time motion analysis measures: The extreme physical demands of match-play in soccer can be determined using information from analyses of repeated intense bouts of running (termed repeated sprint ability) which in turn has implications for conditioning regimens. ${ }^{[31-34]}$ In Study III $^{[13]}$, significant differences exist in the frequency of repeated high-speed bouts (defined as a minimum of three consecutive high-speed actions $>19.8 \mathrm{~km} / \mathrm{h}$ with a mean recovery time of $20 \mathrm{~s}$ separating efforts) across playing positions. On average, fullbacks performed approximately four times 
as many bouts per match compared to central-defenders $(\mathrm{p}<0.001)$. In the former however, only $1.6 \pm 0.8$ bouts per game were observed compared to a mean of $1.1 \pm 1.1$ for all positions. This marginal difference ( +0.5 bouts per match), albeit observed in a single reference team, can again be seen to question the need for position-tailored conditioning programmes. Of interest, the low frequency of repeated high-speed bouts per match observed across all positions in study III is in part accordance with results reported in international male youth players. One-third of players in the Under-17 category for example did not perform a single repeated high-speed bout during match-play. ${ }^{[35]}$ Therefore, these findings therefore question both the relevance of analysing this component of physical performance and its inclusion in fitness testing batteries.

Time motion analyses incorporating the metabolic power concept ${ }^{[36]}$ might be a more sensitive means to identify the high-speed demands respective to playing position. Results from metabolic power analyses of training sessions ${ }^{[37]}$ showed that when acceleration and deceleration activity was accounted for, the high-speed running demands and energy cost were substantially underestimated (for central defenders in particular) by traditional measures of distance travelled at pre-defined speed thresholds. While similar data are currently unavailable for match-play, inferences can be made as to the existence of underestimations of the real demands in competition. Similarly, data from study III ${ }^{[13]}$ not reported here but which merit discussion include the shorter mean recovery times interspersing the individual efforts within repeated high-speed bouts observed in central-defenders in comparison to the other positions $(11.4 \pm 3.7 \mathrm{~s}$ versus a mean of $13.9 \pm 5.4 \mathrm{~s})$. While central-defenders globally performed the lowest number of bouts (Table 1), it seems that when they were called on to perform these, time available for recovery between successive high-speed efforts within the bouts was shorter than for the other positions. These examples highlight the relevance of analysing the intrinsic properties of highspeed running activity and not restricting metrics to simple frequencies and distances covered at predefined speed thresholds.

\subsection{Can time motion analysis data be realistically used to identify the occurrence of fatigue in match-play?}

Two reviews ${ }^{[1,38]}$ of time-motion analyses data for professional soccer competition have provided comprehensive evidence of time-dependent declines in distances covered by players over the course of play. In effect, game profiling generally shows that drops in the total distance covered and/or in high speed running can occur transiently after brief periods of intense activity, overall in the second- versus the first-half and in the final period at the end of play. These reductions have also been associated with declines in running performance in repeated- ${ }^{[39]}$ and $2 \times 20 \mathrm{~m}$-sprint ${ }^{[40]}$ field tests performed during and/or immediately after match-play suggesting the development of transient and accumulated fatigue in players over the course of competition. In contrast, despite time-dependent decrements in physical outputs observed in two studies, these were not associated with a concomitant drop in skill-related proficiency in selected technical actions. ${ }^{[20,22]}$ 
Nevertheless, out of 8 studies $^{[6,11,12,14,16,20,22,23]}$ conducted in contemporary professional soccer competition, a significant drop in total distance run between halves was reported on all but one occasions $^{[12]}$ and the frequency of ball involvements ${ }^{[22]}$ has been shown to diminish in the second-half. Yet when the difference in total distance covered across halves is collated across the studies reporting 'statistically significant' declines, this equates to a mean drop of $-186.0 \pm 97.8 \mathrm{~m}$ or $-3.5 \pm 1.9 \%$ when expressed as a percentage. If this reduction is evaluated from a practical point of view, does a $186 \mathrm{~m}$ drop in total distance run over approximately 45-minutes play realistically suggest a meaningful decline in physical output and the presence of accumulated fatigue in the professional soccer players? There is a need for consensus between practitioners and researchers to define what difference (e.g., percentage drop) in running activity across the two match halves can realistically be considered a meaningful 'impairment' or the 'smallest worthwhile change' relevant for competitive soccer performance. In addition, as the literature tends to demonstrate that a drop in second-half running activity in professional players occurs more commonly than not, one could simply reflect on the practical interest of analysing this metric. In theory, a reduction is likely to be experienced in both teams during play. Therefore any potential advantage due to the deleterious impact of the physical component on some technical and/or tactical game elements would be nullified.

Regarding differences in high-speed activity across halves, contrasting evidence exists with some studies reporting a statistical drop ${ }^{[5,11,20,22,25,41]}$ while others did not. ${ }^{[12,14,16,23]}$ Declines from the $1^{\text {st }}$ - to $2^{\text {nd }}$-half of games are also linked to playing position ${ }^{[5,16]}$ and the time spent by the team in ball possession $^{[22]}$ although discrepancies across studies exist suggesting a need for additional research. For example, in two investigations conducted in English Premier League soccer, one reported the largest decrements in central-defenders and full-backs ${ }^{[16]}$ while the second reported this to be the case in wide-midfielders and attackers ${ }^{[5]}$. In addition, only one study has investigated the association between first- and second-half high-speed activity. ${ }^{[21]}$ While the decrement in distances covered at speeds above $14.4 \mathrm{~km} / \mathrm{h}$ and $19.8 \mathrm{~km} / \mathrm{h}$ during the second half was not a systematic phenomenon, players who performed the most high-speed running in the first-half generally experienced a significant decline in second-half output $(\mathrm{p}<0.05)$. Information on game-to-game variability $(\% \mathrm{CV})$ in declines in running activity across match halves and in the latter stages of games for the team as a whole and across individual playing positions could enable more informed judgements of the practical application of data related to match fatigue.

In future studies, post-match subjective measures of fatigue (e.g., ratings of perceived exertion) would no doubt complement time-motion analysis metrics. There is also a need for conducting pre- and post-match interviews with practitioners and players regarding their adopted 'physical' approach to competition. For example, do players consciously or unconsciously adopt individual pacing strategies ${ }^{[38,42-44]}$ to control physical exertion in an attempt to reduce energy expenditure and maintain second-half performance? Similarly what effect do coaching instructions and ever-evolving game situations (e.g., score line) have on self-imposed physical efforts over the 
course of play? Future research could employ controlled experimental simulations of match-play activity to compare both running performance and physiological responses when players are instructed to operate or not a self-regulated pacing plan.

Numerous investigations ${ }^{[11,16,19,20]}$ have also attempted to determine the existence of accumulated and transient fatigue respectively by comparing high-speed activity usually expressed as distance run during the ultimate 5- and 15-minute intervals of games compared to values for the first and mean of other 5- and 15-minute intervals, and in the 5-minute interval following the 5-minute period during which activity peaked. Statistically significant transient and/or end-game declines in high-speed running distance have been reported, both with and without ball possession, and across each playing position suggesting an attenuation in players' ability to perform such activity. ${ }^{[16]} \mathrm{A}$ recent study has also reported that the distances travelled in intense accelerations and decelerations also exhibited time-dependent reductions from the start to the end of games and immediately after periods of peak activity. ${ }^{[25]}$

Despite the apparent development of fatigue, it is again worthwhile taking a more pragmatic approach to interpreting declines in high-speed activity. The distance covered in running at speeds $>14.4 \mathrm{~km} / \mathrm{h}$ in English Premier League players ${ }^{[16]}$ for example was $17 \%$ less in the last versus the first 15 -minute interval of the second-half $(466 \mathrm{~m} \pm 137$ vs. $374 \mathrm{~m} \pm \mathrm{s} 119, \mathrm{p}<0.01)$. Is it really reasonable though to compare physical performance between the first and final game periods owing to the recognised frantic nature of the former when teams wish to 'engage' and "register their presence" with the opposition. ${ }^{[29]} \mathrm{A}$ comparison with the distance generally covered across over a 15 -minute match period may enable a more objective evaluation of declines. To illustrate this, distance covered at highspeeds in the same Premier League cohort was $45 \%$ lower in the 5-minute period immediately following the 'peak' 5-min interval $(231 \pm 53 \mathrm{~m}$ vs. $126 \pm 52 \mathrm{~m})$. However, when the former was compared to the mean distance covered across all 5-minute periods (minus peak period) only a 6\% drop compared to 'habitual' 5-minute performance was observed despite the reported significant difference ( $\mathrm{p}<0.05,134 \pm 35 \mathrm{~m}$ vs. $126 \pm 52 \mathrm{~m}$ or $-8 \mathrm{~m}$ over 5 -minutes play).

On the basis of the above discussion, one can ask whether time motion analysis data can realistically be used in isolation to identify occurrence of player fatigue represented by simple changes in distance covered across selected time intervals. A major concern with many of the studies that have reported the existence of transient or end game fatigue in match-play is the failure to account for the numerous extrinsic and intrinsic factors recognised as affecting time motion data. ${ }^{[1,27,44]}$ Ideally, confounding factors such as temporal changes in a team's and opposition's tactics and playing system, ball possession and score line and the contributions of substitutions should be incorporated into the statistical approach which up to now has not been achieved. One commonly neglected but key feature is changes in the time the ball is in play over the course of competition. ${ }^{[45]}$ For example, greater distances were observed in high-speed running $(>14.4 \mathrm{~km} / \mathrm{h})$ during the first 5 -minute period of play versus the final 5-minute period and in the peak 5-minute period versus the following 5-minute period 
in French professional players (both $\mathrm{p}<0.05$ ). ${ }^{[20]}$ However, the time the ball was in play was significantly higher in the first and peak 5 -min periods (both $\mathrm{p}<0.05$ ) thus opportunities to work 'physically' were less in the final and following 5-min periods respectively. In addition, pre-defined game intervals (e.g., 0-5 minutes) commonly used as opposed to 'rolling' analyses are associated with less accurate representations of decrements in high-speed running performance over short periods of play. ${ }^{[46]}$

Two methods that could potentially improve interpretation of the magnitude of timedependent declines in physical activity include the systematic consideration of players' individual physiological capacity ${ }^{[47]}$ and the concomitant collection of time-motion analysis data with associated physiological responses to exercise ${ }^{[48]}$ using portable electronic tracking devices such as Global Positioning Systems (GPS). Regarding the latter, if the external (e.g., distance covered) and internal loads (e.g., heart rate) are measured simultaneously using GPS then (irrespective of whether distance covered has dropped later in the game or not) the data can indicate whether the player is working harder physiologically to produce the same external physical output. Attention must be paid however when interpreting data as increased heart rate responses above what is expected for a given running speed during 'normal' running conditions (e. g., continuous runs with no changes of direction or pace) can occur due to common events such as accelerations, decelerations, turns, jumps, backwards/sideways movements and playing the ball as well as changes in psychological and emotional stress. Research using the aforementioned metabolic power concept ${ }^{[37]}$ has recently shown that overall distances covered are only a partial index of overall energy expenditure as acceleration/decelerations phases can increase energy expenditure for the same distance run by up to $15 \%{ }^{[36]}$ Unfortunately, the wearing of portable monitoring devices is currently forbidden in professional soccer competition. Should researchers and club practitioners therefore be lobbying the game's authorities to permit the use of such devices to aid future research and enhance understanding of physical performance, player fatigue and even injury predisposition?

\subsection{Conclusion}

As part of the contemporary soccer coaching process, empirical information from time motion analyses of physical performance in competition is considered essential to provide a platform upon which objective decisions for fitness training and game preparation can be made. However, this article has raised questions about current observations and opinions presented in the scientific literature arising from time-motion analyses of professional soccer competition. In light of this, doubts can be cast as to the real importance of physical performance in relation to success (determined by League ranking) and the extent to which time-motion metrics can be used to determine whether players actually experience fatigue during match-play. Similarly, further reflection regarding data-driven approaches to analysing and interpreting position-specific demands and their eventual application in fitness training interventions is also necessary. 
There is still potential for researchers and coaching practitioners to extend the body of knowledge and attempt to confirm or disprove the present observations. Research is necessary to define a single match work load index to combine and quantify macroscopic motion analysis data with microscopic information containing discrete but physically taxing game actions. There is a need to improve the current holistic approach to data analysis by evaluating interactions between and within running movements especially brief intense efforts along with other factors such as running economy, physiological responses to exercise, and on the ball activities. Inclusion in the statistical model of the many potential confounding factors that can affect physical performance discussed in this article is necessary but up to now has not been adequately achieved. As highlighted throughout this article, the major difficulty will nevertheless remain in objectively relating findings to match-related fatigue, position-specific requirements, subsequent training prescriptions and ultimately competitive success.

\section{References}

1. Carling C, Bloomfield J, Nelsen L, et al. The role of motion analysis in elite soccer: Contemporary performance measurement techniques and work-rate data. Sports Med 2008; 38: 839-62.

2. Strudwick T, Reilly T. Work-rate profiles of elite premier league football players. Insight FA Coaches Assoc J 2001; 4: 55-9.

3. Cazorla G, Zazoui M., Boussaidi L, et al. Étude des exigences physiologiques et biologiques $\mathrm{du}$ match de football et conséquences pour l'évaluation et la préparation physique du footballeur. In Zoudji B, editor. Science et Football: Recherches et Connaissances Actuelles; Valenciennes, France: Presses Universitaires de Valenciennes. 2009: 349-55

4. Di Salvo V, Baron R, González-Haro C, et al. Sprinting analysis of elite soccer players during European Champions League and UEFA Cup matches. J Sports Sci 2010; 28: 1489-94

5. Di Salvo V, Gregson W, Atkinson G, et al. Analysis of high intensity activity in Premier League soccer. Int J Sports Med 2009; 30: 205-12

6. Rienzi E, Drust B, Reilly T, et al. Investigation of anthropometric and work-rate profiles of elite South American international soccer players. J Sports Med Phys Fitness 2000; 40: 162-69

7. Vigne G, Gaudino C, Dellal A, et al. Physical outcome in a successful Italian Serie-A soccer Team over 3 consecutive seasons. J Strength Cond Res 2013; 27: 1400-06.

8. Faude O, Koch T, Meyer T. Straight sprinting is the most frequent action in goal situations in professional football. J Sports Sci 2012; 30: 625-31

9. Apor P. Successful formulae for fitness training. In: Reilly T, Lees A, Davids K, et al., editors. Science and football. London: E\&FN Spon, 1988; 95-107

10. Wisløff U, Helgerud J, Hoff J. Strength and endurance of elite soccer players. Med Sci Sports Exerc 1998; 30: 462-7

11. Mohr M, Krustrup P, Bangsbo J. Match performance of high-standard soccer players with special reference to development of fatigue. J Sports Sci 2003; 21: 519-28.

12. Di Salvo V, Baron R, Tschan $\mathrm{H}$, et al. Performance characteristics according to playing position in elite soccer. Int J Sports Med 2007; 28: 222-27

13. Carling C, Dupont G, Le Gall F. Analysis of repeated high-intensity running performance in professional soccer. J Sports Sci 2012; 30: 325-6.

14. Barros RML, Misuta MS, Menezes RP. et al. (2007). Analysis of the distances covered by first division Brazilian soccer players obtained with an automatic tracking method. J Sports Sci Med 6, 233-42

15. Bloomfield J, Polman RCJ, O'Donoghue PG. Physical demands of different positions in FA Premier League soccer. J Sports Sci Med 2007; 6: 63-70

16. Bradley PS, Sheldon W, Wooster B, et al. High-intensity running in English FA Premier League soccer matches. J Sports Sci 2009; 27: 159-68 
17. Bradley PS, Di Mascio M, Peart D, et al. High-intensity activity profiles of elite soccer players at different performance levels. J Strength Cond Res 2010; 24: 2343-51

18. Dellal A, Chamari K, Ahmaidi S, et al. Physical and technical performance in European soccer match-play: FA Premier League and La Liga. Eur J Sports Sci 2010; 11: 51-9

19. Di Mascio M, Bradley PS. Evaluation of the most intense high-intensity running periods in English FA Premier League soccer matches. J Strength Cond Res 2013; 27: 907-15

20. Carling C, Dupont G. Are declines in physical performance associated with a reduction in skill-related performance during professional soccer match-play? J Sports Sci 2011; 21: 63-7.

21. Rampinini E, Coutts AJ, Castagna C, et al. Variation in top level soccer match performance. Int J Sports Med 2007; 28: 1018-24

22. Rampinini E, Impellizzeri FM, Castagna C, et al. Technical performance during soccer matches of the Italian Serie A league: Effect of fatigue and competitive level. J Sci Med Sport 2009; $12: 227-33$

23. Dupont G, Nedelec M, McCall A, et al. Effect of 2 soccer matches in a week on physical performance and injury rate. Am J Sports Med 2010; 38: 1752-58

24. Di Salvo V, Pigozzi F, González-Haro C, Laughlin MS, De Witt JK. Match Performance Comparison in Top English Soccer Leagues. Int J Sports Med. 2013; in press.

25. Akenhead R, Hayes PR, Thompson KG, French D. Diminutions of acceleration and deceleration output during professional football match play. J Sci Med Sport. 2013; doi: 10.1016/j.jsams.2012.12.005

26. Buchheit M, Simpson BM, Mendez-Villanueva A. Repeated high-speed activities during youth soccer games in relation to changes in maximal sprinting and aerobic speeds. Int $\mathbf{J}$ Sports Med. 2013; 34:40-8

27. Carling C, Williams AM, Reilly T. The Handbook of Soccer Match Analysis. London: Routledge, 2005

28. Reilly T, Thomas V. A motion analysis of work-rate in different positional roles in professional football match-play. J Hum Mov Stud 1976; 2: 87-9

29. Bangsbo J, Nørregaard L, Thorsøe F. Activity profile of competition soccer. Canadian Journal of Sports Science 1991; 16: 110-16

30. Lovell R, Abt G. Individualisation of Time-Motion Analysis: A Case-Cohort Example. Int J Sports Physiol Perform 2012 in press.

31. Girard O, Mendez-Villanueva A, Bishop D. Repeated-sprint ability - Part I factors contributing to fatigue. Sports Med 2011; 41: 673-94

32. Spencer M, Bishop D, Dawson B. et al. Physiological and metabolic responses of repeatedsprint activities: specific to field-based team sports. Sports Med 2005; 35: 1025-44

33. Glaister M. Multiple sprint work: physiological responses, mechanisms of fatigue and the influence of aerobic fitness. Sports Med 2005; 35: 757-77

34. Bishop D, Girard O, Mendez-Villanueva A. Repeated-sprint ability - Part II recommendations for training. Sports Med 2011; 41: 741-56

35. Buchheit M, Mendez-Villanueva A, Simpson BM, et al. Repeated-sprint sequences during youth soccer matches. Int J Sports Med 2010; 31: 709-16

36. Osgnach C, Poser S, Bernardini, et al. Energy cost and metabolic power in elite soccer: a new match analysis approach. Med Sci Sports Exerc 2010; 42: 170-178

37. Gaudino P, Iaia FM, Alberti G, Strudwick AJ, Atkinson G, Gregson W. Monitoring Training in Elite Soccer Players: Systematic Bias between Running Speed and Metabolic Power Data. Int J Sports Med in press

38. Reilly T, Drust B, Clarke N. Muscle fatigue during football match-play. Sports Med 2008; 38: 357-67

39. Krustrup P, Mohr M, Steensberg A, et al. Muscle and blood metabolites during a soccer game: Implications for sprint performance, Med Sci Sports Exerc 2006; 38: 1165-74

40. Rampinini E, Bosio A, Ferraresi I, et al. Match-related fatigue in soccer players. Medicine \& Science in Sports \& Exercise 2011; 43: 2161-270

41. Vigne $\mathrm{G}$, Gaudino $\mathrm{C}$, Rogowski I, et al. Activity profile in elite Italian soccer team. Int $\mathbf{J}$ Sports Med 2010; 31: 304-10 
42. Carling C, Bloomfield J. The effect of an early dismissal on player work-rate in a professional soccer match. J Sci Med Sport 2010; 13: 126-28

43. Edwards AM, Noakes TD. Dehydration: cause of fatigue or sign of pacing in elite soccer? Sports Med 2009; 39: 1-13

44. Drust, B, Atkinson G, Reilly T. Future perspectives in the evaluation of the physiological demands of soccer. Sports Med 2007; 37: 783-805

45. Lago-Peñas C, Rey CE, Lago-Ballesteros J. The Influence of Effective Playing Time on Physical Demands of Elite Soccer Players. Open Sports Sciences Journal 2012; 5: 188-92

46. Varley MC, Elias GP, Aughey RJ. Current match analysis techniques can underestimate intense periods of high-velocity running. Int J Sports Phys Perf 2012; 7: 183-85

47. Carling C, Le Gall F, Dupont, G. Are aerobic fitness and repeated sprint ability linked to fatigue in soccer match-play? In: Book of Abstracts, Third World Congress on Science and Soccer. Ghent: 2012: 140

48. Carling, C., \& Bloomfield, J. Time-motion analysis. In: O’Donoghue, P, Sampaio J, McGarry T, editors. Handbook of Performance Analysis of Sport. London: Routledge, 2012; 283-96 
Table I. Examples of time motion analysis data on high-speed running activity across playing positions.

\begin{tabular}{|c|c|c|c|c|c|c|c|c|}
\hline Study & Authors & High-speed running performance & $\begin{array}{l}\text { Fullbacks } \\
\text { (FB) }\end{array}$ & $\begin{array}{l}\text { Central-defenders } \\
\text { (CD) }\end{array}$ & $\begin{array}{l}\text { Central-midfielders } \\
(\mathrm{CM})\end{array}$ & $\begin{array}{l}\text { Wide-midfielders } \\
\text { (WM) }\end{array}$ & $\begin{array}{l}\text { Attackers } \\
\text { (A) }\end{array}$ & Main observation \\
\hline \multirow[t]{2}{*}{$\mathrm{I}$} & Bradley et al. $^{16}$ & $\begin{array}{l}\text { Total high-speed distance run }(\mathrm{m}) \\
(\text { actions }>19.8 \mathrm{~km} / \mathrm{h})\end{array}$ & $984 \pm 195$ & $603 \pm 132$ & $927 \pm 245$ & $1214 \pm 251$ & $955 \pm 231$ & ${ }^{\mathrm{a}} \mathrm{WM}>$ all positions \\
\hline & & $\begin{array}{l}\text { Recovery time between high-speed runs (s) } \\
\text { (actions }>19.8 \mathrm{~km} / \mathrm{h} \text { ) }\end{array}$ & $74 \pm 23$ & $101 \pm 15$ & $62 \pm 19$ & $51 \pm 16$ & $73 \pm 22$ & ${ }^{\mathrm{a}} \mathrm{CM}=\mathrm{WM}>$ all positions \\
\hline \multirow[t]{2}{*}{ II } & Di Salvo et al. ${ }^{4}$ & $\begin{array}{l}\text { Frequency of explosive sprint accelerations } \\
\text { (actions }>25.2 \mathrm{~km} / \mathrm{h} \text { ) }\end{array}$ & $7.2 \pm 5.5$ & $4.5 \pm 4.2$ & $6.3 \pm 5.8$ & $8.4 \pm 6.3$ & $7.2 \pm 5.7$ & ${ }^{\mathrm{b}} \mathrm{WM}=\mathrm{A}=\mathrm{FB}>\mathrm{CD} ; \mathrm{WM}>\mathrm{CM}$ \\
\hline & & $\begin{array}{l}\text { Frequency of leading sprint accelerations } \\
\text { (actions }>25.2 \mathrm{~km} / \mathrm{h} \text { ) }\end{array}$ & $22.2 \pm 8.5$ & $12.8 \pm 6.0$ & $17.3 \pm 8.2$ & $27.4 \pm 9.5$ & $22.8 \pm 8.8$ & ${ }^{\mathrm{b}} \mathrm{WM}>$ all positions \\
\hline III & Carling et al. ${ }^{13}$ & *Frequency of repeated high-speed bouts & $1.6 \pm 0.8$ & $0.4 \pm 1.1$ & $1.3 \pm 0.6$ & $1.4 \pm 1.1$ & $0.6 \pm 0.8$ & ${ }^{\mathrm{c}} \mathrm{FB}=\mathrm{WM}=\mathrm{CM}>\mathrm{CD}=\mathrm{A}$ \\
\hline
\end{tabular}

Data are presented as means \pm sd

Statistical differences across playing positions: $a=p<0.05 ; b=p<0.001 ; c=p<0.01-p<0.001$

*A minimum of three consecutive high-speed runs (actions $>19.8 \mathrm{~km} \mathrm{~h}^{-1}$ ) with a mean recovery time of 20 s separating efforts 